\title{
Issues and discussions around networked learning
}

Reports from discussion sessions

\section{INTRODUCTION}

A key feature of the Conference was the use of Panel Sessions designed to foster discussion amongst the participants. As a contrast to paper sessions, presenters spoke briefly pointing out the key issues in their work, to stimulate discussion by all in the room. Thus discussion was further encouraged by the comments from reactors and also the chair. This active involvement of all conference attendees in the debate is a feature of IFIP working group meetings and conferences. The seriousness with which the community takes these discussions is evidenced by their inclusion in this book. The notes and reflections from the rapporteurs of these five sessions collaboration in learning, virtual school, teacher education and pedagogic reflection, Internet and the teacher's role, and envisioning the challenges for future teaching.

\section{COLLABORATION IN LEARNING}

Chair: Raymond Morel, $\mathrm{CH}$

Presenters: Lasse Lipponen, FI, Paul Nicholson, AU and Anne

McDougall, AU

Rapporteur: David Squires

\subsection{Promoting educational change with computer-supported collaborative learning}

This presentation by Lasse Lipponene was based on the findings of a series of case studies of the use of computer-supported collaborative learning in Finnish elementary schools. The challenges for innovation identified through this work include overcoming technical problems, coming to terms with new pedagogical approaches, and organising schools so that 
they can realise the benefits of computer-supported collaborative learning. An interesting concept of 'cognitive responsibility' was introduced. In collaborative environments learners have joint responsibilities. As such they need to consciously consider how they can help each other and contribute to the common learning aims. In this context the behaviour of 'lurkers' and dominant group members is critical.

\subsection{Linking science thinking and learning with software}

In this presentation the use of a collaborative hypertext environment for learning science was discussed (MetaMap) by Paul Nicholson. The design of this cognitive tool is based on an extension of the idea of a concept map to three dimensions. It is claimed that this extension attends to problems inherent in conventional concept maps: they are hard to up-date, interpret, relate to other concept maps, concept clusters are often 'off screen' in complex maps, and the complexity of maps is often confusing. The role of the map is to act as a 'voice' for learners, providing a mechanism for them to articulate and express their ideas. These expressions can then be used in collaboration with other learners (and teachers) to provide a framework for debate and collaborative learning.

\subsection{Issues in learning with new technologies}

The idea of the interface as a partner in learning was explored in this session by Anne McDougall. A simple example of drawing a circle was used to illustrate this idea. The conventional way to draw a circle is to use a compass. The use of this physical 'interface' to the act of drawing implies at least an intuitive appreciation of the concepts of radius and circumference with the consequent implications for mathematical understanding. This approach was contrasted with two computer based techniques for drawing a circle. First the use of Logo to programme procedures for drawing circles was considered. Procedures can be written which utilise the concept of radius. However, the more natural approach, which resonates with the 'differential geometry' inherent in Logo is the well known 'poly procedure' approach, which does not invoke the concept of radius. Second, the use of a drawing tool, based on the direct manipulation of a square envelope, was discussed. In this last technique there is no implicit mathematical content, as defined in conventional mathematical curricula. Is the use of such tools counter-productive in encouraging and supporting learning, or has the nature of knowledge (in this case the structure and construction of circles) been changed by the advent of ICT? 


\subsection{Some issues for consideration}

\subsubsection{Collaboration in learning}

Collaboration for learning is a complex idea, and dimensions of this complexity emerged in the discussion. First, there was agreement that the experiences of collaborating learners are often different. An unattractive feature of some collaborative ventures is that major and minor roles may be assigned (sometimes unconsciously) to group members, e.g. a less dominant/able member of a group may be assigned the task of acting as typist when a small group of learners is using software. Issues of concern here are a realisation of cognitive responsibility, with more able dominant members of a group accepting mentoring and supporting roles for other members. In a distributed context anonymity is an important aspect anonymous disccurse can lead to a 'level playing field' environment in which all members have an equal voice and responsibility during collaboration.

Second, there is an issue of whether collaborative learning is simply an environment for individuals to learn in, providing scope for learners to develop their own personal conceptions by 'bouncing ideas' off other people. In this conception, the group does not learn as such; rather individuals are assisted to make personal developments. In contrast, notions of distributed cognition open up the idea of the collaboration resulting in the group learning as whole, with knowledge and an understanding developing in the 'spaces' between the collaborators.

It may be a matter of semantics, but it could be helpful to distinguish between collaboration and co-operation as a way of highlighting these issues. Collaboration is characterised by an awareness of cognitive responsibility and an acceptance of conceptually defined learning owned by a group of collaborators. Co-operation is characterised by a focus on personal idiosyncratic conceptual development with the assignment of roles (beneficial or otherwise) to group members.

\subsubsection{Assessment}

Assessment in collaborative contexts is problematic. Well rehearsed concerns are typically focused on who did the work, and who should get most credit in a group. Of course, this implies an outcomes oriented approach to assessment, and fails to realise the scope for personally tuned formative assessment focused on learning processes. However, if collaborative learning is to become a 'respected' mainstream approach to learning, summative evaluation needs to be addressed. In this context, the 
notion of group assessment in which all members grades are moderated in terms of the average grade obtained by the group is interesting. In such approaches, in a group that does well as a whole, all members will benefit, perhaps leading to an awareness of the benefits of cognitive responsibility. Of course, the reverse moderating effect holds, also making possible highlighting the importance of cognitive responsibility.

\subsubsection{Software features}

A strong point was made that 'fitness for purpose' is very important - the appropriateness of software design depends on what you intend to do with the software. Thus if you want to draw many circles of different colours and sizes to represent balloons on a poster, the use of a drawing tool makes sense. If you are a mathematics teacher trying to teach the concept of radius, the use of a compass or purpose designed procedures in Logo makes sense. In fact, a useful teaching technique may be to give students different procedures, which reflect radial and non-radial definitions of circles.

A subtle but important point emerged in the discussion about the nonneutrality of computer interfaces. It was claimed that the MetaMap software provides a collaborative voice to learners. In a sense this implies that the learners are using the software much as a ventriloquist would use a dummy. However, software is not a dummy - it has all sorts of features and possibilities inherent in its design. In fact some writers would go so far to sat that it has intrinsic intelligence of a sort. Thus, the collaborative voice of the learner will be interpreted in this frame of designed inherent possibilities. The consequent potential and limitations determined by the frame need to be taken account of. This leaves us with an important question: Who is driving the design of software designed to support collaboration: the designer (and by implication the commercial producer), the teacher, or the collaborator?

\section{VIRTUAL SCHOOL}

Chair: Peter Bollerslev, DK

Presenters: David Passig, IL, Wolfgang Weber and Annemarie HaufTulodziecki, DE

Reactors: Doug Brown, UK, and Anne McDougall, AU

Rapporteur: Brian Samways, UK

\subsection{Virtual reality and a new media for learning}

In the first paper, David Passig and Aviva Sharbat reported on their research into the views of 50 experts on the future of virtual reality (VR) in 
education. Although it was an ad-hoc group, it did have persons from 11 different countries most of whom held key positions in universities, research institutions or industries involved in educational virtual reality. Five key themes emerged from the paper: VR is a powerful breakthrough and needs an alternative classroom structure; VR is cognitively different but can solve existing problems; VR offers new learning styles; VR has great potential in science and language learning; and teachers require specific training for VR.

The second paper given by Wolfgang Weber and Annemarie HaufTulodziecki focused on media literacy. The concept, based on their research findings, is a framework within which schools can find their own developmental position. On completing their action plans for media literacy the project team were able to identify gaps. These were filled by bringing the ideas of different schools together and supporting the interchange. Four key themes emerged from the paper: new media for learning; analysis of planned use across the whole school; sharing good practice between schools; and bringing schools together and encouraging joint working.

\subsection{Reactors}

Doug Brown stated that clearly these are exciting times and there is an increasing need for collaboration. It is interesting to note that we often over estimate impacts of new technology in the short-term when predicting the future, but under estimate these in the long term. We need to re-visit 'what is education' more frequently, as all too often we use our own experiences as a base and these quickly become out-of-date with the fast developments. Do we react and respond to the technology or use the new technologies to deliver our educational choice? We too should ask ourselves whether or not we are addressing the use of the new media and how we integrate these into our already overloaded curriculum.

Anne McDougall said that there is a really strong message that it was correct to put these two papers together on the conference programme. The second speaker Wolfgang Weber is talking about virtual reality as can be clearly seen in his diagram on Work Area. We researchers must be aware that the next steps are often defined by the 'doers' but that the vision from the second presentation provides a very strong pointer to the ways in which virtual reality might be implemented.

\subsection{Key issues in discussion}

The audience was reminded that in 1983 it was reported that there was disappointment in the introduction of IT into education in that it was only a continuation of 'chalk and talk'. However, that was IT in two dimensions and with VR we now have a three-dimensional approach and this will ensure 
the future breakthrough. We must also go forward using evolutionary steps and not revolutionary ones. It was also said that over the years we have 'poured' computers into schools but they still are not being used effectively. Currently we are trying to use our research to develop the future by creating a vision.

The implementation of such systems must be made as simple as possible; for example, 'one button' operations. In the German project 'Schools to the Net' showed the potential of the Internet and how computers can be used sensibly when connected. New Media has over 4000 programmes but only about 100 have the potential to improve the quality of learning. Teachers still use the 'drill and practice' press button type, but they are trying to get them to integrate the computer in the learning process. Delegates could visit the 'Fairy Tales on the Web' site (in English) at: http://www.learnline.de

Personal; experiences supported the discussion. One delegate related two of her own experiences. In one she used a computer chemical model but found it offered no more than a real model which could be used in the classroom. In the other she viewed a VR art gallery and in one mode it was possible for her to experience the exhibition in the same way as the partially sighted creator. The second experience could not have been experienced in any other way.

Those present were reminded that the 'biro' when first invented, was sold with the promotion that it could write under water. It was a very useful invention but we still do not write under water. In the same way virtual reality has great potential but the promotion of it may not indicate the future direction.

\section{TEACHER EDUCATION, PEDAGOGICAL REFLECTION}

Chair: Peter Bollerslev, DK

Presenters: Gail Marshall, US, and Don Passey, UK

Reactors: Harriet Taylor, US, and Rosa Maria Bottino, IT

Rapporteur: Brian Samways, UK

\subsection{Connecting teaching and learning}

In the first paper Gail Marshall emphasised the need for teaching to 'make meaning' and she gave several examples where ICT could complement good pedagogical practice. She reminded the audience of the need to create a 'web' between teaching and learning using the tools of the mind. She felt there are four 'technologies' of the mind, which were generally not being addressed in today's technology equipped classrooms and finished with a concern for those teachers who because the work was hard for their pupils often did the thinking for them. Two key themes 
emerged: there is a need to create a web between teaching and learning; and there are four technologies of the mind - planning, memory, representation and inference.

Don Passey continued the connection between teaching and learning, in his paper but from the need for a vision, a plan and implementation. In the UK links between schools and community are being encouraged; there are resources being created for the web; the new national curriculum is reviewing the need for ICT skills; and both pre-service and in-service teacher education are being re-examined. However there is no support at present for a 'connected learning community'. Four key themes emerged: the need for a vision, a plan and implementation; teachers, pupils and parents can be extended; laptops between school and home are beneficial; and a connected society will place greater demands on all of us.

\subsection{Reactors}

Harriet Taylor said that clearly we have to capture the models of use where it is being done well and transfer these ideas to our work. More resources need to be allocated, but in ways which will be successful. Big ideas and big projects have done well, but translating that to our small individual work is difficult, and as always the politicians want results as soon as the hardware is in place. Using ICT we need better models, and in the light of the useful questions that have been posed by our speakers we now need the answers. The experts are probably here at this conference and we should discuss seriously the out-of-school learning.

Rosa Maria Bottino suggested that the 'Connected Learning Community' is a good way to describe a learning society and we have firstly to convince teachers of the benefits of connecting learners. There has to be a new professionalism in using ICT tools across the curriculum with a view to addressing cognitive skills. Couple this with the need for awareness of the role that ICT can play in the teaching and learning processes it is clear that the form, content and practice of teacher training needs to be revised. In the end schools must use ICT effectively, support pupils, parents and the community and develop ways of supporting the school-home connection. Clearly roles are changing, learning evaluation is changing and new models of analysis (hopefully using ICT) are necessary.

\subsection{Key issues in discussion}

Two questions were raised how and where do we try to motivate pupils? Similarly with the difficulties raised in the second paper, as we cannot rectify all of these in one full swoop. But often there is enough excitement and enthusiasm to keep the changes going. If changes are meaningful they 
will continue and we do not need to continually control. Also we have evidence that teachers do not have to be school connected. Nearly half are already down the path in the State of Jersey. We need evaluation but some of these proposed changes are not great. For example, homework set by teachers is often not related to current schoolwork. We must somehow make schoolwork and homework more related. It is important to work on a small scale at school level and with the local community. The new curriculum in the United Kingdom is not technologically originated; it does emphasis the "I" in ICT. When ICT is put in the hands of children their competencies increase enormously. Two years' advancement has been shown in secondary education and three years in terms of desktop applications for year 6 in elementary.

However concern was also expressed that harnessing students' out-ofschool time is Fascist, and that it is important that we not only create students that fit into society but that we encourage informal learning at all times. Using the description 'learning in the wild' she felt that homework should be loosened from schoolwork. Another remarked that it is difficult enough to be a good teacher, let alone a good parent. We should make more use of other local organisations such as public libraries with their professional staff. Parents are not professional and are pulled in many different directions by advertising for example.

It was added that in ICT it is the style of learning and the approach to the computer that are important. Some approaches do not capture the hearts of teachers, only their minds. Those teachers who listened on the other hand would certainly buy the message and their children would take it home, adding the caveat that this is not the whole answer. Yet learning is at the centre of importance today and that to be able to work with the 'big' ideas in learning, one must have 'big' ideas in both content and process. The audience was asked to think of what kind of support they would not want to give. The audience was also reminded of small-scale projects and the local research into such initiatives where the results challenge the national picture. These have a technical contribution to make to the larger picture.

In conclusion we may have lots of 'vision' but as yet not enough thought has been given to the strategic planning. But head the mistake in tackling the alphabet, a letter at a time and missing the enormous advancement of seeing it as a whole. "We must be careful not to jettison good directed pedagogy for the sake of using ICT". 
5.

\section{THE IMPACT OF THE INTERNET ON THE ROLE OF} THE TEACHER

Chair: David Benzie, UK

Presenters: Petra Wager, FI, and Yvonne Buettner, $\mathrm{CH}$

Reactor: Helene Godinet, FR

Reporter: Paul Nicholson, AU

\section{$5.1 \quad$ Teachers' roles}

The use of the Internet in education is growing rapidly, and its application to the curriculum has broadened to cover all curriculum areas. This rapid change and growth in usage has been largely driven by external influences, rather than by pedagogical or educational needs grounded in the classroom. It has had a major impact on teachers and school systems who are not necessarily prepared for the challenges this presents.

Petra Wager discussed the role of the teacher and the emergence of distance education in Finnish schools. A sociological analysis of the role of the teacher in Internet-based classrooms shows that teachers' work has undergone significant changes in response to the demands of the medium, requiring a wide range of competencies beyond those of the traditional classroom. In particular, the teacher is no longer 'just' a teacher but must adopt a multiplicity of roles such as developer, technician, curriculum developer, and secretary, In order for effective implementation to occur, issues specific to each of these new roles must be addressed.

Yvonne Buttner discussed how new skills and competencies are required in addition to those acquired earlier. Teachers need extensive support in implementing these new technologies. It is essential that educators determine the role and value of the Internet in education, and develop appropriate pedagogical and ICT skills in order to facilitate its effective implementation.

\subsection{Key issues}

The impact of ICT and particularly the Internet has been to significantly change the nature of teachers' work, not only within the classroom, but also by creating new demands on teachers' time outside of the classroom and school. The role has been broadened from a focus on delivering prepackaged curriculum content to the students, to becoming - a secretary (managing information); a content creator; a researcher or consultant; a curriculum developer; a publisher; a technical expert; or a student (need to keep learning simply to do their job with the new media). 
There is a major professional concern about how much can be expected of an individual teacher. Should the demands of the technology require them to undertake unpaid work out of school simply because developing resources for the Internet is so time intensive? If not, then how will school systems fund such development at the local level? If they can't provide funds, is it ethical to expect teachers to do it for free? What industrial and professional issues and pressures need to be raised here?

In distance education, there is the additional issue of distributed expertise, for example, in working with remote schools, who should determine the nature and content of curriculum materials - the local school or central provider? Is it important to draw on local (school-based) expertise, or should a central agency be responsible for all decision making? In either case, what is it that the teachers in each location have to know, and must be able to do with the technology? The critical issue here is that if individual teachers are expected to create, publish, and deliver content, how will they be supported in acquiring the necessary competencies and time?

These issues require real solutions. For example, it is quite likely that teachers will not be able to teach effectively, if at all, with ICT if they do not have access to a computer and current software at home so that they can become 'Internet literate' through personal exploration of the Internet's potential outside of the workplace - they need to have an opportunity to explore the medium in the same way as they developed their traditional pedagogical skills by working in classrooms. The common assumption that traditional pedagogy can simply be transferred to the Internet is not realistic: there is a strong need to know what works, and what does not work well, in online course delivery, and so be able to create appropriate learning activities and learning environments. Of particular importance in this regard is the need to develop communicative processes and strategies so that learning is facilitated by human communication and interaction rather than relying solely on the technology to do the teaching.

\subsection{Conclusions}

It is clear that effectively addressing the issues above requires extensive support to allow the teacher to develop the required competencies. This has significant financial implications, and even with the best of financial support, may not lead to effective change because of the individual teacher's inability to commit the time needed to conceptualise, create, and publish Internet-based curriculum materials

It is recommended that a workgroup approach be adopted in which the school, and not the individual teacher, becomes the focus for support and development. This may simplify financial considerations, and provide a 
more durable development model. Within a school, different staff members may acquire specific skills and knowledge that will support the educational endeavours of the whole school. In this way individual teachers are not burdened with the need to acquire a diverse range of skills, but can call on colleagues when specific support is needed. In addition, the distributed nature of the knowledge in the school means that the loss of a single teacher does not remove the whole set of skills and knowledge from the school. The school therefore becomes both a learning community of its own, with its own experts to assist its teachers, and the facilitator of an external learning community. In this way, support structures and processes become a normal part of its structure, and so serve to sustain the changes that prompted their development.

6. THE CHALLENGES FOR FUTURE TEACHING

Chair: Sindre Rosvig, NO

Contributors: Petra Fisser, NL, Andrea Kö and Andras Gabor, HU, and Larry Miller, CA

Reactor: Giovanna Gazzaniga, IT

Rapporteur: Rosa Maria Bottino, IT

\subsection{The challenge of change}

The first two papers, by Petra Fisser and Andrea Ko, stressed the necessity that education, and, in particular, higher education have to meet the requirements of the networked society. Opportunities offered together with some disadvantages were discussed and examples of good practice were proposed.

For example, the University of Twente has a long tradition in the use of telematics applications and, at present, the task force 'Telematics application in education' has been formed with the aim of stimulating and initiating new projects. The aim is to use telematics to support the learning process and not to go in the direction of a virtual university. Petra Fisser emphasised that the vision which is at the basis of this project at present is that the industry sector has the need for university graduates who are prepared in using information and communication technology in their future profession. The objective of the work done at the University of Twente is to offer more flexible learning environments which are not meant to replace the instructor but where their role progressively changes - from lecturer to guide. Of course this passage is not a simple one and the teachers have to be supported in this change and in using ICT applications: the 'Telematic Studio' has been established at this regard. More details about this quite innovative project could be found at: http:/teletop.edte.utwente.nl 
Andrea Kö started from the same assumption of Petra, that education cannot be separated from the business and economy; it is influenced by market and by the new changes in technology. It has to consider the strong need that industries and companies have of ICT skilled persons. Of course, university, and education, in general, could not be only concerned with the present interests of the occupational market but need to have a strategic vision of the future knowledge society. Schools and educational institutions need to radically re-engineer their traditional activities. Andrea suggested two main streams that seem her decisive at this regard: the individual learning through the lifelong studies, and the remote/virtual college.

Larry Miller presented a vision of the future teaching that is grounded into a different background, that of primary education. From this perspective he outlined two possible views: a) the curricula embedded in software seen as a lever to move teachers toward new approaches to teaching, and b) the curricula, designed by experts, embedded in software, and then delivered to students using classic programmed instructional principles. Different premises and visions of future teaching can suggest different answers to some crucial questions: The technological refusal is a guilty of teachers? Who is in charge of technological innovations? Will technology make schools and teachers irrelevant?

\subsection{Reactor}

Giovanna Gazzaniga reacted to these contributions and outlined some possible problems and possibilities. She started from the consideration that using ICT in education is mandatory now and that teachers must face the problem of how to introduce ICT in their teaching activity. This brought her to some initial questions: are we sure that teachers are well informed about new possibilities? Can we consider the scenarios presented by Petra and Andrea as 'normal'? And, generally speaking, how ICT can be introduced in the teaching activity? As far as this last question is concerned, she delineated three different situations: i) teachers who work alone and simply adapt their usual approach to teaching to ICT environment ('Internet tolerant curricula') ii) teachers who work alone and try to exploit some of the new opportunities offered by ICT, and iii) teachers who work relying on the support of expert institutions. Each of the three outlined situations has both positive and negative aspects, and, often, teachers cannot choose among them.

Some of the questions that Giovanna then raised considered not only the teacher but also the learner's point of view. Is it always good for students to handle new technologies even if ICT are merely used as a substitute of a 
quite traditional approach to education? Could students refuse ICT if they perceived them as a way for saving money or teachers time?

\subsection{Discussion}

The discussion that followed these briefly sketched issues and questions involved all the audience, conveniently stimulated by the chairman, and mainly developed around the following questions.

Teachers should be prepared to the fact that students have competencies in ICT uses and opportunities to use them by their own. School is usually slower than external reality.

How can we give to the students all the support they need for effective learning through the use of ICT with short time at disposal? The use of ICT do not usually saves time but instead increases the time required.

Can computers become a discriminating media? Do we adequately consider gender problems? Are different attitudes sufficiently valorised?

Is it now teachers or student time? 